\title{
Analisis Risiko Beban Kerja Pekerja Usaha Bubuk Kopi Cap Matahari
}

\author{
Muhammad Ilham Adelino'), Nurasyiah'2) \\ ${ }^{1}$ Fakultas Teknik, Universitas Putra Indonesia "YPTK", Padang \\ email: milhamadelino@gmail.com \\ ${ }^{2}$ Fakultas Teknik, Universitas Putra Indonesia "YPTK", Padang \\ email: nurasyiah333@gmail.com
}

\begin{abstract}
Usaha Bubuk Kopi Cap Matahari is a small-size enterprise that produces coffee powder in West Pasaman Regency. The problem was all workers in sorting and concoction station suffering from sore on shoulders, waist, upper and lower arms. The aim of this study was to identify and measure level of workers workload risk using the revised NIOSH Lifting Equation. The results were calculated initial Recommended Weight Limit ( $R W L$ ) ranged from 11,71 to 21,05, final RWL ranged from 6,50 to 19,80, initial Composite Lifting Index (CLI) ranged from 1,33 to 2,39 and final CLIs ranged from 1,41 to 4,31. CLI score above one (CLI > 1) indicates level of workers workload risk exceeded the recommended CLI. The suggested solutions were reducing lifting load and improving the lifting method. The new CLIs score after improvement ranged from 0,51 to 0,97.
\end{abstract}

Keywords: NIOSH, workload, RWL, CLI, CVL

\begin{abstract}
Abstrak
Usaha bubuk Kopi Cap Matahari adalah suatu usaha skala kecil yang memproduksi bubuk kopi yang berdomisili di Kabupaten Pasaman Barat. Masalah yang terjadi adalah seluruh pekerja pada stasiun kerja sortir dan perendangan mengalami sakit pada bagian bahu, pinggang, lengan atas, dan lengan bawah. Tujuan dari penelitian ini adalah untuk mengidentifikasi dan mengukur level risiko beban kerja pada pekerja tersebut menggunakan revised NIOSH Lifting Equation. Hasil yang didapat adalah hasil perhitungan pada Recommended Weight Limit (RWL) awal berkisar antara 11,71 dan 21,05, RWL akhir antara 6,50 dan 19,80, Composite Lifting Index (CLI) awal antara 1,33 dan 2,39, dan CLI akhir adalah 1,41 dan 4,31. Nilai CLI diatas satu (CLI > 1) mengindikasikan bahwa level risiko beban kerja mengalami kelebihan dari nilai CLI yang direkomendasikan $(\mathrm{CLI}<1)$. Untuk mengatasi hal tersebut, solusi yang disarankan adalah dengan mengurangi beban angkat dan memperbaiki metode pengangkatan. Nilai CLI setelah dilakukan saran perbaikan adalah berkisar antara 0,51 dan 0,97 .
\end{abstract}

Kata kunci: NIOSH, Beban kerja, RWL, CLI, CVL

\section{PENDAHULUAN}

Tubuh manusia dirancang untuk dapat melakukan aktivitas pekerjaan sehari-hari. Adanya massa otot yang bobotnya hampir lebih dari separuh beban tubuh, memungkinkan kita untuk dapat menggerakkan dan melakukan pekerjaan. Pekerjaan disatu pihak mempunyai arti penting bagi kemajuan dan peningkatan prestasi, sehingga mencapai kehidupan yang produktif sebagai satu tujuan hidup. Bekerja berarti tubuh akan menerima beban dari luar tubuhnya.

Usaha Bubuk Kopi Cap Matahari merupakan industri kopi yang terletak di $\mathrm{Jl}$. Kuburan Nan Duo Jorong Murni Panti Kecamatan Panti Kabupaten Pasaman Timur. Usaha Bubuk Kopi Cap Matahari ini sudah memiliki pasar yang terbilang luas, Usaha Bubuk Kopi Cap Matahari memiliki beberapa pekerjaan yang harus 
dilaksanakan pada waktu pengolahan kopi. Pekerjaan yang dilakukan terdiri dari mengangkat, menurunkan, mendorong, menarik dan membawa merupakan sumber utama komplain karyawan di industri. Pekerjaan yang dilakukan pada Usaha Bubuk Kopi Cap Matahari ini masih menggunakan tenaga manusia tanpa menggunakan alat bantu. Jadi apabila pekerjaan yang dilakukan tidak tepat maka dapat menimbulkan kerugian bahkan kecelakaan pada karyawan.

Berdasarkan kuesioner yang telah dikumpulkan, seluruh pekerja mengalami masalah muskuloskeletal pada bagian bahu, pingang, lengan atas dan lengan bawah. Sebagian besar pekerjaan-pekerjaan yang dilakukan berhubungan dengan aktivitas mengangkat dan menurunkan beban. Beban angkat yang dilakukan oleh setiap pekerja adalah sebesar $28 \mathrm{~kg}$ dalam satu kali angkat. Untuk mengetahui tingkat risiko beban kerja atas setiap pekerjaan-pekerjaan tersebut, metode Revised NIOSH Lifting Equation dapat digunakan.

Pengukuran beban kerja menggunakan NIOSH Lifting Equation sudah pernah dilakukan dalam beberapa penelitian terdahulu. Dalam penelitian beban kerja yang dilakukan terhadap operator visual pada PT. Jappro Batam didapatkan hasil bahwa berat beban angkat pada tiga orang operator visual tersebut tidak melebihi batas berat beban yang disarankan dan tidak mengandung risiko cidera tulang belakang meskipun mengalami cedera otot rangka pada bagian pundak [1]. Banyaknya keluhan dari pekerja stasiun pengemasan di PT. Petrosida Gresik menjadi dasar untuk dilakukan analisis menggunakan metode NIOSH dan didapatkan hasil nilai LI lebih besar dari 1 sehingga perusahaan perlu melakukan perbaikan pada beban angkat [2]. Dalam beberapa penelitian, metode NIOSH Lifting Equation juga efektif dalam mengurangi masalah muskuloskeletal dan risiko sakit pada punggung [3][4]. Salah satu faktor yang mempengaruhi LI adalah konsumsi energi saat pengangkatan [5]. Mendekatkan beban lebih dekat ke tubuh, meninggikan ketinggian objek, dan mendekatkan jarak antara asal dan tujuan adalah langkah-langkah yang dapat dilakukan saat nilai LI lebih tinggi dari 1 (satu) [6]

NIOSH (National for Occupational Safety and Health) adalah suatu lembaga yang menangani masalah kesehatan dan keselamatan kerja di Amerika. NIOSH membuat suatu metode yang dapat menjadi acuan dalam mengukur beban kerja yang disebut NIOSH Lifting Equation. Seiring waktu, metode NIOSH Lifting Equation dilakukan beberapa perubahan dan menjadi Revised NIOSH Lifting Equation. Metode Revised NIOSH Lifting Equation adalah bagian dari biomekanika. Tindakan dalam revised NIOSH Lifting Equation adalah berat beban dibawah 16 $\mathrm{kg}$ tidak memerlukan perlakuan khusus, berat beban $16-25 \mathrm{~kg}$ perlu perhatian khusus, dan berat beban melebihi $25 \mathrm{~kg}$ perlu perhatian pada metode pengangkatan atau perlu bantuan peralatan mekanis [7][8][9]. Sistem kerja dapat menjadi pertimbangan dalam memperbaiki permasalahan dalam pekerjaan bertenaga manusia [10].

Adapun tujuan dari penelitian ini adalah dapat mengidentifikasi tingkat risiko pekerjaan mengangkat dan menurunkan beban pada pekerja Usaha Bubuk Kopi Cap Matahari berdasarkan Revised NIOSH Lifting Equation dan memberikan solusi beban yang dapat diterapkan kepada pekerjanya.

\section{METODE PENELITIAN}

Jenis penelitian yang dilakukan adalah penelitian kuantitatif, dimana data berbentuk angka-angka, dan dapat dilakukan analisis berdasarkan prosedur statistika. Adapun teknik sampling dalam pengumpulan sampel adalah menggunakan sampling jenuh dan seluruh populasi menjadi sampel dalam penelitian ini. Data yang dikumpulkan terdiri dari data primer 
terkait postur tubuh meliputi pekerja pengukuran jarak horizontal $(\mathrm{H})$, jarak vertikal $(\mathrm{V})$, sudut asimetrik (A), titik awal beban (D), jumlah beban diangkat per menit $(\mathrm{F})$, dan momen gaya $(\mathrm{C})$. Jumlah pekerja yang menjadi sampel penelitian adalah sebanyak 6 orang, dimana 3 orang dari stasiun kerja sortir dan 3 orang dari stasiun kerja perendangan.

\section{HASIL DAN PEMBAHASAN}

Setelah dilakukan pengumpulan data, selanjutnya dilakukan pengolahan data dengan metode Revised NIOSH Lifting Equation dengan tahapantahapan sebagai berikut:

3.1. Perhitungan Recommended Weight Limit $(R W L)$ untuk setiap pekerja

Bagian ruang sortir biji kopi yang kering dan bagian perendangan memiliki berat beban angkat $28 \mathrm{~kg}$ per karung biji kopi. Setiap pekerja dilakukan pengamatan, pencatatan, dan dokumentasi postur tubuh pekerja dalam melakukan aktivitas mengangkat dan menurunkan karung biji kopi tersebut. Hasil dokumentasi dilakukan pengukuran untuk mendapatkan besaran jarak horizontal $(\mathrm{H})$, jarak vertikal (V), sudut asimetrik (A), titik awal beban (D), jumlah beban diangkat per menit $(\mathrm{F})$, dan momen gaya (C). Data $\mathrm{H}$ digunakan untuk menghitung Horizontal Multiplier (HM), data V untuk menghitung Vertical Multiplier (VM), data D untuk menghitung Distance Multiplier (DM), data A untuk menghitung Asymetric Multiplier (AM), data C untuk menghitung Coupling Multiplier (CM), dan data F untuk menghitung Frequency Multiplier (FM). Berdasarkan hasil perhitungan RWL, besar berat beban yang disarankan adalah antara $6,50 \mathrm{~kg}$ dan $21,05 \mathrm{~kg}$. Untuk hasil perhitungan faktor pengali dan RWL dapat dilihat pada tabel 1 dan 2 .

Tabel 1. Faktor Pengali setiap pekerja

\begin{tabular}{|c|c|c|c|c|c|c|c|}
\hline \multirow{2}{*}{ Pkj } & \multirow{2}{*}{ Ps } & \multicolumn{6}{|c|}{ Faktor Pengali } \\
\cline { 3 - 8 } & & HM & VM & DM & AM & CM & FM \\
\hline
\end{tabular}

\begin{tabular}{|c|c|c|c|c|c|c|c|}
\multirow{2}{*}{$\mathrm{A}$} & 1 & 0.83 & 1.162 & 1.008 & 1 & 1 & 0.84 \\
\cline { 2 - 8 } & 2 & 0.78 & 1.069 & 1.229 & 1 & 1 & 0.84 \\
\hline \multirow{2}{*}{$\mathrm{B}$} & 1 & 0.83 & 1.162 & 0.849 & 1 & 1 & 0.91 \\
\cline { 2 - 8 } & 2 & 0.78 & 0.739 & 1.229 & 0.904 & 1 & 0.91 \\
\hline \multirow{2}{*}{$\mathrm{C}$} & 1 & 0.93 & 1.162 & 1.008 & 1 & 1 & 0.84 \\
\cline { 2 - 8 } & 2 & 0.86 & 1.069 & 1.229 & 0.712 & 1 & 0.84 \\
\hline \multirow{2}{*}{$\mathrm{D}$} & 1 & 0.69 & 1.159 & 0.859 & 1 & 1 & 0.75 \\
\cline { 2 - 8 } & 2 & 0.66 & 0.952 & 0.863 & 0.712 & 1 & 0.75 \\
\hline \multirow{2}{*}{$\mathrm{E}$} & 1 & 0.68 & 1.159 & 0.861 & 1 & 1 & 0.75 \\
\cline { 2 - 8 } & 2 & 0.64 & 0.958 & 0.863 & 0.712 & 1 & 0.75 \\
\hline \multirow{2}{*}{$\mathrm{F}$} & 1 & 0.69 & 1.159 & 0.861 & 1 & 1 & 0.75 \\
\cline { 2 - 8 } & 2 & 0.66 & 0.952 & 0.863 & 0.712 & 1 & 0.75 \\
\hline
\end{tabular}

3.2. Perhitungan Composite Lifting Index (CLI) untuk setiap pekerja

Setelah mendapatkan nilai RWL, selanjutnya dilakukan perhitungan CLI untuk mendapatkan tingkat risiko beban kerja pada setiap pekerja. Perhitungan CLI didapatkan dari nilai RWL dibagi dengan berat beban angkat. Berdasarkan hasil perhitungan CLI, seluruh pekerja memiliki nilai CLI diatas 1 (satu). Jika nilai CLI bernilai diatas 1 (satu), maka beban angkat yang dilakukan oleh pekerja, baik pada stasiun kerja sortir dan perendangan, sudah melebihi dari berat beban yang disarankan. Jika berat beban ini tetap terus dilakukan, maka akan memberi dampak buruk pada tulang belakang. Untuk itu perlu dilakukan perbaikan segera agar pekerja dapat terhindar dari risiko kesehatan pada tulang belakang.

\subsection{Solusi yang dapat diterapkan}

Untuk mengurangi level risiko dan mencegah masalah kesehatan pada tulang belakang, terdapat du acara yang dapat dilakukan, yaitu:

Tabel 2. Nilai CLI untuk setiap pekerja

\begin{tabular}{|c|c|c|c|}
\hline Pkj & Beban & Nilai RWL & Nilai CLI \\
\hline
\end{tabular}




\begin{tabular}{|c|c|c|c|c|c|}
\hline & $\begin{array}{c}\text { Angkat } \\
(\mathrm{kg})\end{array}$ & 1 & 2 & 1 & 2 \\
\hline A & 28 & 18,78 & 19,80 & 1,491 & 1,414 \\
\hline B & 28 & 17,14 & 13,40 & 1,634 & 2,089 \\
\hline C & 28 & 21,05 & 15,54 & 1,330 & 1,802 \\
\hline D & 28 & 11,85 & 6,66 & 2,363 & 4,204 \\
\hline E & 28 & 11,71 & 6,50 & 2,392 & 4,309 \\
\hline F & 28 & 11,88 & 6,66 & 2,357 & 4,204 \\
\hline
\end{tabular}

3.3.1. Melakukan pengurangan berat beban angkat per karung biji kopi

Pengurangan beban angkat dilakukan karna beban yang diangkat setiap operator baik bagian ruang sortir dan ruang perendangan sudah melebihi beban angkat yang direkomendasikan berdasarkan perhitungan RWL. Berat beban angkat untuk stasiun kerja sortir diturunkan menjadi $13 \mathrm{~kg}$ dan untuk stasiun kerja perendangan diturunkan menjadi $6 \mathrm{~kg}$. Penurunan tersebut didasarkan atas nilai RWL terkecil dari setiap stasiun kerja. Estimasi hasil CLI dari tindakan pencegahan tersebut dapat dilihat pada tabel 3 .

\subsubsection{Memperbaiki metode pengangkatan}

Metode pengangkatan beban dapat dilakukan dengan pengangkatan manual dan menggunakan alat bantu. Jika menggunakan alat bantu, maka perlu menganggarkan sejumlah dana untuk membeli alat bantu tersebut. Untuk pengangkatan manual masih perlu dilakukan, maka dapat dilakukan pengangkatan dengan mendekatkan beban dengan tubuh pekerja. Hal ini dapat mengurangi nilai HM sehingga terjadi penurunan nilai HM pada setiap pekerja atau dengan memperbaiki sudut asimetrik saat melakukan pengangkatan dan menurunkan beban. Tindakan ini dapat menurunkan nilai AM sehingga menjadi $0^{\circ}$. Untuk melihat besaran nilai CLI berdasarkan perbaikan metode pengangkatan tersebut, dapat dilihat pada tabel 4 dan 5 .

Tabel 3. Berat beban angkat yang disarankan dan nilai LI per pekerja

\begin{tabular}{|c|c|c|c|c|c|}
\hline \multirow{2}{*}{ Pkj } & \multirow{2}{*}{$\begin{array}{c}\text { Beban } \\
\text { Angkat }\end{array}$} & \multicolumn{2}{|c|}{ Nilai RWL } & \multicolumn{2}{c|}{ Nilai CLI } \\
\cline { 3 - 6 } & $(\mathrm{kg})$ & 1 & 2 & 1 & 2 \\
\hline A & 13 & 18,78 & 19,80 & 0,69 & 0,66 \\
\hline B & 13 & 17,14 & 13,40 & 0,76 & 0,97 \\
\hline C & 13 & 21,05 & 15,54 & 0,62 & 0,84 \\
\hline D & 6 & 11,85 & 6,66 & 0,51 & 0,90 \\
\hline E & 6 & 11,71 & 6,50 & 0,51 & 0,92 \\
\hline F & 6 & 11,88 & 6,66 & 0,51 & 0,90 \\
\hline
\end{tabular}

Tabel 4. Nilai Faktor Pengali per pekerja

\begin{tabular}{|c|c|c|c|c|c|c|c|}
\hline \multirow{2}{*}{ Pkj } & Ps & HM & VM & DM & AM & CM & FM \\
\hline \multirow{2}{*}{ A } & 1 & 1 & 1.16 & 1.01 & 1 & 1 & 0.84 \\
\cline { 2 - 8 } & 2 & 1 & 1.07 & 1.22 & 1 & 1 & 0.84 \\
\hline \multirow{2}{*}{ B } & 1 & 1 & 1.16 & 0.85 & 1 & 1 & 0.91 \\
\cline { 2 - 8 } & 2 & 1 & 0.74 & 1.23 & 1 & 1 & 0.91 \\
\hline \multirow{2}{*}{ C } & 1 & 1 & 1.16 & 1.01 & 1 & 1 & 0.84 \\
\cline { 2 - 8 } & 2 & 1 & 1.07 & 1.23 & 1 & 1 & 0.84 \\
\hline \multirow{2}{*}{ D } & 1 & 1 & 1.16 & 0.86 & 1 & 1 & 0.75 \\
\cline { 2 - 8 } & 2 & 1 & 0.95 & 0.86 & 1 & 1 & 0.75 \\
\hline \multirow{2}{*}{ E } & 1 & 1 & 1.16 & 0.86 & 1 & 1 & 0.75 \\
\cline { 2 - 8 } & 2 & 1 & 0.96 & 0.86 & 1 & 1 & 0.75 \\
\hline \multirow{2}{*}{ F } & 1 & 1 & 1.16 & 0.86 & 1 & 1 & 0.75 \\
\cline { 2 - 8 } & 2 & 1 & 0.95 & 0.86 & 1 & 1 & 0.75 \\
\hline
\end{tabular}

Tabel 5. Nilai CLI berdasarkan perbaikan metode pengangkatan

\begin{tabular}{|c|c|c|c|c|c|}
\hline \multirow{2}{*}{ Pkj } & \multirow{2}{*}{$\begin{array}{c}\text { Beban } \\
\text { Angkat } \\
\end{array}$} & \multicolumn{2}{|c|}{ Nilai RWL } & \multicolumn{2}{c|}{ Nilai CLI } \\
\cline { 3 - 6 } & $(\mathrm{kg})$ & 1 & 2 & 1 & 2 \\
\hline A & 28 & 22,63 & 25,38 & 0,81 & 0,91 \\
\hline B & 28 & 20,65 & 19,01 & 0,74 & 0,68 \\
\hline C & 28 & 22,63 & 25,38 & 0,81 & 0,91 \\
\hline D & 28 & 17,17 & 14,17 & 0,61 & 0,51 \\
\hline E & 28 & 17,21 & 14,26 & 0,51 & 0,61 \\
\hline F & 28 & 14,26 & 17,21 & 0,51 & 0,62 \\
\hline
\end{tabular}




\section{SIMPULAN}

Tingkat resiko pekerjaan pada Usaha Bubuk Kopi Cap Matahari berdasarkan ketentuan Revised NIOSH Lifting Equation adalah masih teridentifikasi resiko adanya cedera punggung jika dilihat dari hasil perhitungan nilai Composite Lifting Index (CLI). Nilai CLI pada pekerja melebihi dari 1 (satu) sehingga diperlukan perbaikan segera. Perbaikan yang dilakukan dapat dilakukan dengan mengurangi berat beban sesuai dengan berat beban yang disarankan atau dengan memperbaiki metode pengangkatannya. Penelitian ini masih dapat dilanjutkan dan dikembangkan dengan mempertimbangkan fisiologi kerja pada pekerja.

\section{DAFTAR PUSTAKA}

[1] Bora, M.A., Azhari, D. 2015. Analisa Beban Kerja Pada Operator Visual Dengan Pendekatan Recommended Weight Limit (RWL) Di PT. Jappro Batam. ILTEK, 10, 1405-1410. doi: https://doi.org/10.47398/iltek.v11i01.406

[2] Resdianti, M.C., Handoko, L., Juliana, A.I. 2016. Analisa Beban Kerja Pekerja Tahapan Pengemasan Unit Padatan PT. Petrosida Gresik dengan Metode Recommeded Weight Limit (RWL). Seminar Nasional Maritim, Sains dan Teknologi Terapan, 01, 25481509

[3] Shahu, R. 2016. The NIOSH Lifting Equation for Manual Lifting and Its Applications. Journal of Ergonomics, 6 (2), pp. 1-10. doi: 10.4172/2165-7556.1000159

[4] Elfeituri, F.E., Taboun, S.M. 2015. An
Evaluation of the NIOSH Lifting Equation: A Psychophysical and Biomechanical Investigation. International Journal of Occupational Safety and Ergonomics, 8 (2), pp. 243-258. doi: https://doi.org/10.1080/10803548.2002.1107 6527

[5] Ranavolo, A., Varrecchia, T., Rinaldi, M., Silvetti, A., Serrao, M., Conforto, S., Draicchio, F. 2017. Mechanical Lifting Energy Consumption in Work Activities Designed by Means of the "Revised NIOSH Lifting Equation". Industrial Health, 55, pp. 444-454.

doi: https://doi.org/10.2486/indhealth.2017-0075

[6] Meepradit, P., Sunee, N., Chantrasa, R. 2015. The Apllication of NIOSH Lifting Equation to Prevent Muskuloskeletal Disorder Risks. Journal of Biosciences and Medicines, 3, 39-44. doi: http://dx.doi.org/10.4236/jbm.2015.33006

[7] Iristiadi, H., \& Yassierli. (2014). Ergonomi Suatu Pengantar. Bandung: PT Remaja Rosdakarya

[8] Tarwaka. (2015). Ergonomi Industri, DasarDasar Pengetahuan Ergonomi Dan Aplikasi Di Tempat Kerja. Surakarta: Harahap Press.

[9] Wignjosoebroto, S. (2006). Ergonomi Studi Gerak dan Waktu. Surabaya: Prima Printing

[10] Yanto. (2017). Ergonomi Dasar-Dasar Studi Waktu \& Gerakan Untuk Analisis \& Perbaikan Sistem Kerja.Yogyakarta: Andi Offset 